\title{
Effect of cardiopulmonary bypass on the pharmacokinetics of propranolol and atenolol
}

\author{
M.J.C. Carmona1, V.A. Pereira ${ }^{2}$, L.M.S. Malbouisson ${ }^{1}$, J.O.C. Auler Jr. ${ }^{1}$ and \\ S.R.C.J. Santos ${ }^{2}$ \\ ${ }^{1}$ Serviço de Anestesiologia e Terapia Intensiva Cirúrgica, \\ Instituto do Coração, Faculdade de Medicina, ${ }^{2}$ Departamento de Farmácia, Faculdade de Ciências \\ Farmacêuticas, Universidade de São Paulo, São Paulo, SP, Brasil
}

Correspondence to: M.J.C. Carmona, Serviço de Anestesiologia e Terapia Intensiva Cirúrgica, Instituto do Coração, HC, FM, USP, Av. Dr. Enéas C. Aguiar, 44, 2ํo andar, 05403-000 São Paulo, SP, Brasil

Fax: +55-11-3082-2354. E-mail: maria.carmona@incor.usp.br

The pharmacokinetics of some $\beta$-blockers are altered by cardiopulmonary bypass (CPB). The objective of this study was to compare the effect of coronary artery bypass graft (CABG) surgery employing CPB on the pharmacokinetics of propranolol and atenolol. We studied patients receiving oral propranolol with doses ranging from 80 to $240 \mathrm{mg}(\mathrm{N}=11)$ or atenolol with doses ranging from 25 to $100 \mathrm{mg}(\mathrm{N}=8)$ in the pre- and postoperative period of CABG with moderately hypothermic $\mathrm{CPB}\left(32^{\circ} \mathrm{C}\right)$. On the day before and on the first day after surgery, blood samples were collected before $\beta$-blocker administration and every $2 \mathrm{~h}$ thereafter. Plasma levels were determined using high-performance liquid chromatography and data were treated by pharmacokinetics-modelling. Statistical analysis was performed using ANOVA or the Friedman test, as appropriate, and $\mathrm{P}<0.05$ was considered to be significant. A prolongation of propranolol biological half-life from $5.41 \pm 0.75$ to $11.46 \pm 1.66 \mathrm{~h}(P=0.0028)$ and an increase in propranolol volume of distribution from $8.70 \pm 2.83$ to $19.33 \pm 6.52 \mathrm{~L} / \mathrm{kg}(\mathrm{P}=0.0032)$ were observed after $\mathrm{CABG}$ with CPB. No significant changes were observed in either atenolol biological half-life (from $11.20 \pm 1.60$ to $11.44 \pm 2.89 \mathrm{~h}$ ) or atenolol volume of distribution (from $2.90 \pm 0.36$ to $3.83 \pm 0.72 \mathrm{~L} / \mathrm{kg}$ ). Total clearance was not changed by surgery. These CPBinduced alterations in propranolol pharmacokinetics may promote unexpected long-lasting effects in the postoperative period while the effects of atenolol were not modified by CPB surgery.

Key words: Propranolol; Atenolol; Pharmacokinetics; Coronary artery bypass grafting surgery; Cardiopulmonary bypass

Research supported by FAPESP (\#97/14466-7).

Received April 12, 2008. Accepted February 26, 2009

\section{Introduction}

Several $\beta$-adrenoreceptor antagonists ( $\beta$-blockers) have been used for the treatment of angina, and the choice depends on the selectivity in relation to the type of $\beta$ receptors, antiarrhythmic actions, intrinsic sympathomimetic activity, potency, lipid solubility, blocking of $\alpha$-adrenoceptors, oxidation phenotype, effects on serum lipids, and membrane-stabilizing activity (1). $\beta$-adrenoreceptor antagonists improve acute outcomes and long-term prog- nosis in ischemic heart disease (2) and reduce perioperative events among high-risk patients undergoing major non-cardiac and vascular surgery $(3,4)$. Preoperative $\beta$ blocker therapy has also been shown to reduce the incidence of intraoperative ischemic events related to increases in heart rate and hemodynamic responses to surgical stimulation during coronary artery bypass graft (CABG) $(5,6)$. Administration of a $\beta$-blocker before coronary bypass and its postoperative reinstitution is considered safe and beneficial $(7,8)$, whereas an abrupt with- 
drawal of the drug has been associated with myocardial ischemia, hypertension, and arrhythmia secondary to a $\beta$ blockade-induced increase in $\beta$-receptor density (9).

In patients undergoing CABG, atenolol and propranolol are commonly used $\beta$-blockers and the same drug is usually reintroduced after surgery. Because it is known that the dose of propranolol necessary to obtain an adequate $\beta$-blockade effect in the postoperative period, in order to reduce heart rate to $<100$ beats per minute (bpm), is lower than the preoperative dose, we carried out a clinical study (10) that showed that cardiopulmonary bypass (CPB) alters the kinetic disposition of propranolol in patients undergoing cardiac surgery.

Since the same preoperative dose of atenolol and propranolol is currently used to obtain the same degree of $\beta$-blockade in the postoperative period, we compared the pre- and postoperative pharmacokinetics of propranolol and atenolol in patients with coronary heart disease undergoing coronary artery bypass grafting employing cardiopulmonary bypass under moderate hypothermia.

\section{Material and Methods}

The study protocol was approved by the Hospital Ethics Committee, and written informed consent was obtained from all patients. Patients scheduled for CABG under moderate hypothermic $\mathrm{CPB}$ and receiving propranolol ( $\mathrm{N}$ $=11)$ or atenolol $(N=8)$ preoperatively were enrolled in the study. Inclusion criteria were: a) left ventricular ejection fraction greater than 0.5 and normal right ventricular function assessed by preoperative transthoracic echocardiography in the week preceding surgery; b) normal hepatic and renal function; c) patients with minimal or low surgical risk according to Higgins score (11), as described below. Patients with diabetes mellitus, chronic obstructive lung disease, peripheric arterial vascular disease, or candidates for off-pump CABG were excluded from the study. Surgical risk was preoperatively assessed according to the criteria proposed by Higgins et al. (11), i.e., patients were classified into minimal, low, moderate, high, extreme risk categories. This risk score takes into account the following variables: a) emergency procedure, b) preoperative serum creatinine levels, c) presence of left ventricular dysfunction, d) preoperative hematocrit, e) age, f) chronic pulmonary disease, g) prior vascular surgery, h) reoperation, and i) mitral valve insufficiency. Partial results concerning patients receiving propranolol have been already reported elsewhere (10). Body surface area (BSA) and lean body mass (LBM) were calculated using standard formulas, as follows: BSA $\left(\mathrm{m}^{2}\right)=($ [height $(\mathrm{cm}) \times$ weight $(\mathrm{kg})] / 3600)^{1 / 2} ;$ LBM men $(\mathrm{kg})=(1.10 \mathrm{x}$ weight $(\mathrm{kg}))-128$ $\left(\right.$ weight $\left.{ }^{2} /(100 x \text { height }(\mathrm{m}))^{2}\right)$ and LBM women $(\mathrm{kg})=(1.07$ $\mathrm{x}$ weight $(\mathrm{kg}))-148$ (weight $\left.{ }^{2} /(100 \mathrm{x} \text { height }(\mathrm{m}))^{2}\right)$.

Monitoring, anesthetic and surgical procedures

Each patient received 0.1 to $0.2 \mathrm{mg} / \mathrm{kg}$ midazolam orally 30 min before surgery. After the patient was admitted into the surgical room, electrocardiographic monitoring configured to continuously display the leads II and V5 and pulse oximetry were installed. Invasive arterial pressure monitoring was obtained in the left radial artery using a specific 20-gauge radial catheter (Quickflash set, Arrow, Germany). Anesthesia was induced with 0.3 to $0.5 \mu \mathrm{g} / \mathrm{kg}$ sufentanil, $0.3 \mathrm{mg} / \mathrm{kg}$ midazolam and 0.1 to $0.2 \mathrm{mg} / \mathrm{kg}$ pancuronium bromide and maintained by isoflurane inhalation and supplementary doses of sufentanil and pancuronium bromide. During CPB, hypnosis was obtained using supplementary doses of midazolam. For each patient, tidal volume was set at $8 \mathrm{~mL} / \mathrm{kg}$ and the respiratory rate was adjusted by the anesthesiologist in order to achieve $\mathrm{PaCO}_{2}$ values between 30 and $35 \mathrm{mmHg}$. Inspiratory time representing $33 \%$ of the respiratory cycle total time and an inspired oxygen fraction of 0.60 were maintained throughout surgery. Positive end expiratory pressure of $5 \mathrm{~cm} / \mathrm{H}_{2} \mathrm{O}$ was implemented after intubation and maintained throughout surgery. After anesthetic induction, a nasopharyngeal thermometer, a vesical catheter and a central venous catheter (Multi Med central venous catheter, Edwards Lifesciences, USA) were inserted. When judged necessary by the attending anesthesiologist, a fiberoptic thermodilution pulmonary artery catheter $\left(\mathrm{CCO} / \mathrm{SvO}_{2} / \mathrm{VIP}^{\text {TM }} \mathrm{TD}\right.$ catheter, Edwards Lifesciences) was inserted through the right internal jugular vein.

After opening the chest and dissection of the vascular structures, cannulas were inserted into the aorta and the inferior and superior cava veins. Cardiopulmonary bypass was performed using an extracorporeal circuit and membrane oxygenator primed with lactated Ringer solution (Oxim II-34 Ultra membrane oxygenator, Edwards Lifesciences). After initiation of CPB, patients were cooled and core temperature was maintained at $32-34^{\circ} \mathrm{C}\left(89.6-93.2^{\circ} \mathrm{F}\right)$ until the end of coronary grafting. After rewarming to $37^{\circ} \mathrm{C}$ $\left(98.6^{\circ} \mathrm{F}\right)$, the patients were weaned from CPB. Vasoactive drugs were infused when judged necessary by the attending anesthesiologist. In case of bradycardia with heart rate lower than $60 \mathrm{bpm}$, a pacemaker was installed to maintain cardiac frequency in $80 \mathrm{bpm}$.

\section{Study protocol and $\beta$-blocker measurements}

All patients were chronically receiving $\beta$-blocker orally: propranolol (Inderal ${ }^{\circledR}$, Zeneca, Brazil), with total daily doses ranging from 80 to $240 \mathrm{mg}$ divided into 2-4 times a day or 
atenolol (Atenol ${ }^{\circledR}$, Zeneca), with total daily doses ranging from 25 to $100 \mathrm{mg}$ divided into 1-2 times a day. Immediately before administration of the last preoperative dose of $\beta$-blocker on the night before surgery, a blood sample was collected to measure baseline propranolol or atenolol plasma concentration. Then, the patients received propranolol or atenolol according to their standard dose regimen and other samples were drawn at 2, 4, 6, and $8 \mathrm{~h}$ for preoperative pharmacokinetic modelling. Patients were operated the following morning. Eighteen hours after the end of surgery, on the first postoperative day, when the patients were allowed to drink water, a postoperative baseline blood sample was collected and the same preoperative $\beta$ blocker was administered orally: $10 \mathrm{mg}$ propranolol or 25 $\mathrm{mg}$ atenolol. To model postoperative pharmacokinetics, blood samples were collected at 2, 4, 6, 8, 12, and $24 \mathrm{~h}$. EDTA tubes containing blood samples were centrifuged at $2800 \mathrm{~g}$ and stored at a temperature of $-70^{\circ} \mathrm{C}\left(-158^{\circ} \mathrm{F}\right)$ until measurement of the drug. Heart rate and mean arterial pressure were recorded at admission to the operating room, at the end of surgery, immediately after admission to the intensive care unit, and at 8:00 am on the first and second postoperative days.

Drug assay for propranolol was performed using highperformance liquid chromatography with fluorescence detection (HPLC-F) as described (12). Briefly, plasma propranolol concentration was determined by HPLC-F after a clean up of plasma consisting of a single extraction, by adding $200 \mu \mathrm{L} 1.25 \mathrm{M} \mathrm{NaOH}$ to a glass tube containing 200 $\mu \mathrm{L}$ plasma plus an internal standard (verapamil hydrochloride, $2.5 \mathrm{mg} /$ assay). The mixture was vortexed for $1 \mathrm{~min}$, followed by centrifugation at $2800 \mathrm{~g}$ for $10 \mathrm{~min}$, and the organic phase was immersed in a liquid nitrogen bath. The supernatant was transferred to a conic glass tube and dried to residue in a stream of nitrogen. The residue was then dissolved in $100 \mu \mathrm{L}$ of mobile phase and injected (loop $20 \mu \mathrm{L}$ ) into HPLC-F Shimadzu LC-10A (Shimadzu Corp., Japan), connected to a 4-micron reversed phase column NovaPak ${ }^{\mathrm{TM}} \mathrm{C} 18,150 \times 3.9 \mathrm{~mm}$, adapted to a C18 Nova Pack precolumn insert, $4 \mu \mathrm{m}, 60 \mathrm{~A}$ (Waters Corp., USA). The binary mobile phase consisting of $0.38 \mathrm{M}$ acetate buffer, $\mathrm{pH} 5.0$, and acetonitrile $(65: 35, \mathrm{v} / \mathrm{v})$ was delivered at $0.7 \mathrm{~mL} / \mathrm{min}$, isocratically. Peaks were monitored using a fluorescence detector (RF $10 \mathrm{AXL}$, Shimadzu Corp.) with $290 \mathrm{~nm}$ ( $\lambda$ ex) and $358 \mathrm{~nm}$ ( $\lambda$ em). For the determination of plasma atenolol levels, $200-\mu \mathrm{L}$ plasma aliquots were added to $100 \mu \mathrm{L}$ of internal standard (1.25 $\mu \mathrm{g} / \mathrm{mL}$ sotalol) in 2.0-mL Eppendorf tubes. Plasma proteins were precipitated by the addition of $400 \mu \mathrm{L}$ acetonitrile and homogenized in a tube shaker for $15 \mathrm{~s}$. The tubes were centrifuged at $5600 \mathrm{~g}$ for $30 \mathrm{~min}$ at $5^{\circ} \mathrm{C}$, the superna- tant was decanted, and the residue remaining in the tube was discarded. Aliquots $(200 \mu \mathrm{L})$ of the supernatant (organic-aqueous extract) were transferred to a conic tube and the solvent was evaporated in a water bath under a nitrogen flow at $37^{\circ} \mathrm{C}$. The evaporation residue was dissolved in $200 \mu \mathrm{L}$ of a mixture, water:methanol, 80:20, v/v, and injected automatically into a Shimadzu liquid chromatograph equipped with an LC-10 AD VP pump connected to a C18 Shim Pack column (150 x $4.6 \mathrm{~mm}, 4 \mu \mathrm{m}$; Shimadzu) protected by a C18 Nova Pack precolumn inserts ( $4 \mu \mathrm{m}, 60 \mathrm{~A})$. For separation, a binary mobile phase consisting of $50 \mathrm{mM}$ phosphate buffer, $\mathrm{pH} 5.5$, and methanol $(80: 20, v / v)$ was used at $0.7 \mathrm{~mL} / \mathrm{min}$. The peaks were monitored with an RF 10AXL fluorescence detector at wavelengths of $235 \mathrm{~nm}$ ( $\lambda$ ex $)$ and $290 \mathrm{~nm}$ ( $\lambda$ em). The areas of the peaks were integrated using the Class VP software (Shimadzu) and a CR6A integrator (Shimadzu).

Propranolol and atenolol plasma levels were normalized according to hematocrit values, considering the hemodilution that occurs during CPB. For pharmacokinetics, the software pharmacokinetics solution 2.0 (Pharmacokinetics and Metabolism Software, USA) was applied to estimate the following main kinetic parameters: apparent volume of distribution, total body clearance and biological $\beta$ half-life.

\section{Statistical analysis}

Statistical analysis was performed using the SAS statistical package (SAS Institute Inc., USA). Normal distribution of data was evaluated using the Shapiro-Wilk test and graphic analysis of residual distribution observed by means of normal probabilities graph and box-plot $(13,14)$. If nonnormal data distribution was observed, the data were analyzed using non-parametrical statistical tests. Patient characteristics were compared using the chi-square test, the Fisher exact test and the unpaired Student $t$-test, when appropriate. After confirmation of normal distribution of the $\beta$-blocker plasma concentrations and their logarithmic transformation, pharmacokinetic data before and after surgery in both groups were compared by two-way analysis of variance for repeated measurements. If analysis detected that effect of surgery with CPB on plasma concentrations was different for atenolol and propranolol groups, a comparison of the logarithm of plasma concentration decay slopes of both drugs estimated using a growing curves model was performed in order to compare the behavior of the groups. This type of analysis enabled the modeling of the relationship between the observations made on the same individual pre- and postoperatively.

The hemodynamic variables were compared between the two groups using a two-way analysis of variance for 
Table 1. Demographic and surgical data of the patients.

\begin{tabular}{lcc}
\hline & $\begin{array}{c}\text { Propranolol } \\
\text { group }\end{array}$ & $\begin{array}{c}\text { Atenolol } \\
\text { group }\end{array}$ \\
\hline Gender (male/female) & $7 / 4$ & $6 / 2$ \\
Age (years) & $57 \pm 8$ & $63 \pm 7$ \\
Body weight $(\mathrm{kg})$ & $75.4 \pm 11.9$ & $76.2 \pm 12.9$ \\
Height $(\mathrm{m})$ & $1.64 \pm 0.08$ & $1.65 \pm 0.08$ \\
$\mathrm{BSA}\left(\mathrm{m}^{2}\right)$ & $1.83 \pm 0.19$ & $1.86 \pm 0.2$ \\
LBM $\left(\mathrm{kg} / \mathrm{m}^{2}\right)$ & $28.0 \pm 3.86$ & $27.9 \pm 3.93$ \\
Duration of surgery (min) & $420 \pm 47$ & $365 \pm 45^{*}$ \\
Duration of CPB (min) & $107 \pm 32$ & $82 \pm 23$ \\
Minimal temperature on CPB $\left({ }^{\circ} \mathrm{C}\right)$ & $32.9 \pm 2.3$ & $32.4 \pm 2.5$ \\
Minimal Ht on CPB $(\%)$ & $26.5 \pm 4.6$ & $26.6 \pm 3.3$ \\
ICU length of stay $(\mathrm{h})$ & $48 \pm 15$ & $47 \pm 9$ \\
Postoperative length of stay (days) & $5.8 \pm 1$ & $5.5 \pm 0.6$ \\
\hline
\end{tabular}

BSA = body surface area; LBM = lean body mass; $\mathrm{CPB}=$ cardiopulmonary bypass; $\mathrm{Ht}=$ hematocrit; $\mathrm{ICU}=$ intensive care unit. ${ }^{*} \mathrm{P}<0.05$ compared to propranolol group (chi-square test and unpaired $t$-test).

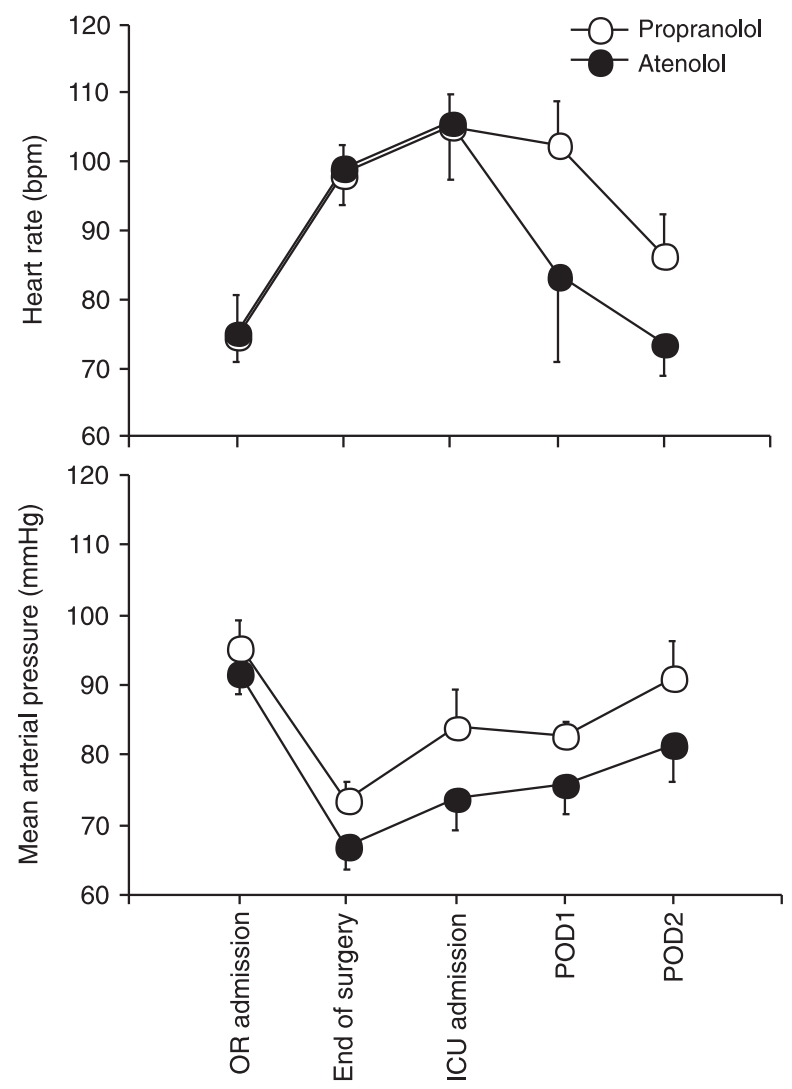

Figure 1. Heart rate and arterial pressure of patients receiving atenolol and propranolol. The patients received atenolol (filled circles, $N=8$ ) or propranolol (open circles, $N=11$ ). $\mathrm{OR}=$ operating room; ICU = intensive care unit. POD1 and POD2 = postoperative days 1 and 2, respectively. repeated measurements. Post hocanalysis was performed using the Student-Newman-Keuls test. Pharmacokinetic parameters before and after surgery were compared by the Friedman test and differences between groups were compared using Wilcoxon tests. All data were reported as mean \pm standard deviation unless otherwise specified. Statistical significance was considered to be $\mathrm{P}<0.05$.

\section{Results}

The characteristics of the patients enrolled in this study are presented in Table 1. Briefly, no differences between the groups were found regarding gender, age or anthropometric measures. Both groups presented minimal or low surgical risk according to criteria proposed by Higgins et al. (11). All patients included in the study presented a normal preoperative creatinine clearance $(85.07 \pm 11.59 \mathrm{~mL} / \mathrm{min}$ in the propranolol group and $83.37 \pm 23.99$ in the atenolol group). Hepatic function assessed by the prothrombin time was normal for both groups, with a mean of $13.59 \mathrm{~s}$ (ranging from 11.7 to $16.1 \mathrm{~s}$ ) for the propranolol group and $13.83 \mathrm{~s}$ (from 12.3 to $15.1 \mathrm{~s}$ ) for the atenolol group. The duration of surgery was greater for the propranolol group but the duration of CPB was comparable in both groups as well as minimal temperature achieved during CPB (Table 1). The degree of hemodilution during CPB indicated by the fall in initial hematocrit from $40.1 \pm 3.6$ to $26.5 \pm 4.6 \%$ in the propranolol group and from $40.8 \pm 2.3$ to $26.6 \pm 3.3 \%$ in the atenolol group was also similar. Dobutamine infusion in doses lower than $5.0 \mu \mathrm{g} \cdot \mathrm{kg}^{-1} \cdot \mathrm{min}^{-1}$ was necessary in 3 patients of the propranolol group and in 2 patients of the atenolol group during the weaning from CPB. Nitroglycerine and sodium nitroprusside were administered as necessary for arterial pressure control. All patients achieved hemodynamic stability in the immediate postoperative period, permitting the weaning from vasoactive drugs within $18 \mathrm{~h}$. As shown in the upper panel of Figure 1, there was an increase in heart rate after CPB by the second postoperative day, returning to preoperative baseline values immediately after patient admission to the operating room. No significant differences were observed between groups. Mean arterial pressure was lower immediately after CPB returning to preoperative levels at the end of observation time in both groups, without significant differences between them (lower panel of Figure 1). One patient of each group presented acute atrial fibrillation after discharge from the intensive care unit. No episodes of bradycardia were observed during the study and there was no need for postoperative pacemaker support. As shown in Table 1, no differences were observed in the intensive care unit or overall postoperative length of stay. 

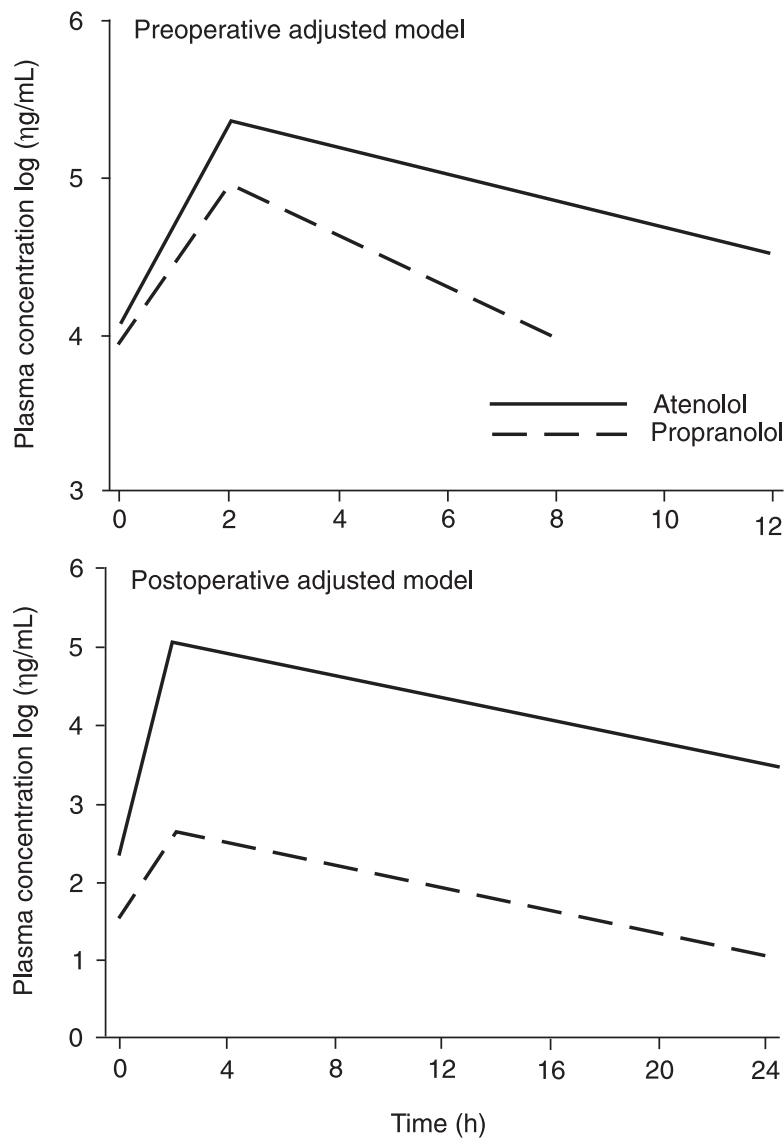

As can be seen in the adjusted model of growing curves presented in the upper panel of Figure 2, the fall of preoperative plasma levels of propranolol, shown as the descending dashed slope, was significantly steeper than the fall in
Figure 2. Adjusted model of log plasma concentration of atenolol (continuous line) and propranolol (dashed line) during the preoperative and postoperative periods of coronary artery bypass graft surgery with cardiopulmonary bypass. The slopes of the decaying phase of the log plasma concentration of atenolol preand postoperatively were -0.08 and -0.11 , respectively. For preand postoperative decaying concentrations of propranolol, the slopes were -0.16 and -0.08 , respectively.
Table 2. Pharmacokinetics of propranolol and atenolol during the pre- and postoperative periods of coronary artery bypass graft surgery with cardiopulmonary bypass.

\begin{tabular}{lcc}
\hline Pharmacokinetic parameter & $\begin{array}{c}\text { Preoperative } \\
\text { period }\end{array}$ & $\begin{array}{c}\text { Postoperative } \\
\text { period }\end{array}$ \\
\hline Biologcial $\beta$ half-life $(\mathrm{h})$ & & \\
$\quad$ Atenolol $(\mathrm{N}=8)$ & $11.2 \pm 4.5$ & $11.4 \pm 8.2$ \\
$\quad$ Propranolol $(\mathrm{N}=11)$ & $5.4 \pm 2.5^{+}$ & $11.5 \pm 8.2^{*}$ \\
Apparent volume of distribution $(\mathrm{L} / \mathrm{kg})$ & & \\
$\quad$ Atenolol $(\mathrm{N}=8)$ & $2.9 \pm 1.0$ & $3.8 \pm 2.0$ \\
$\quad$ Propranolol $(\mathrm{N}=11)$ & $8.7 \pm 9.4^{+}$ & $19.3 \pm 21.6^{+*}$ \\
$\quad$ Total body clearance $\left(\mathrm{mL} \cdot \mathrm{min}^{-1} \cdot \mathrm{kg}^{-1}\right)$ & $3.6 \pm 1.8$ & \\
$\quad$ Atenolol $(\mathrm{N}=8)$ & $16.1 \pm 14.3^{+}$ & $17.2 \pm 16.0^{+}$ \\
$\quad$ Propranolol $(\mathrm{N}=11)$ &
\end{tabular}

${ }^{+} P<0.05$, significantly different compared to atenolol. ${ }^{*} P<0.05$, significantly different compared to preoperative period (two-way repeated measures ANOVA followed by Student-Newmann-Keuls post-hoc test). plasma levels of atenolol $(-0.16$ vs $-0.08 ; \mathrm{P}=0.01)$. Conversely, on the first day following surgery, as presented in the postoperative adjusted model of plasma concentration (lower panel of Figure 2), the propranolol plasma decay slope was similar to that presented for atenolol $(-0.08 v s-0.11)$. When pre- to postoperative pharmacokinetic data from atenolol and propranolol were compared, a $111 \%$ increase (from $5.4 \pm 2.5$ to $11.5 \pm 8.2 \mathrm{~h}$ ) in postoperative propranolol biological $\beta$ half-life was observed while no alterations were observed in atenolol biological $\beta$ half-life (from $11.2 \pm 4.5$ to $11.4 \pm 8.1 \mathrm{~h}$ ). The apparent volume of distribution of propranolol significantly increased by $121 \%$ in the first postoperative day (from $8.7 \pm 9.4$ to $19.3 \pm 21.6 \mathrm{~L} / \mathrm{kg}$ ) compared with preoperative values while atenolol volume of distribution presented an increase of $31 \%$ (from $2.9 \pm$ 1 to $3.8 \pm 2 \mathrm{~L} / \mathrm{kg}$ ). No alterations were observed in postoperative total body clearance for atenolol or propranolol, as shown in Table 2. Furthermore, no relationship was observed between the length of $\mathrm{CPB}$ or esophageal temperature during $\mathrm{CPB}$ and pharmacokinetic parameters. 


\section{Discussion}

In this study, a significant increase in the biological $\beta$ half-life and in the apparent volume of distribution of propranolol in patients undergoing surgery with hypothermic CPB was observed, with total body clearance of propranolol unchanged. Conversely, atenolol pharmacokinetics was not significantly affected by CPB (Table 2). No relationship was found between the duration of CPB or temperature during $\mathrm{CPB}$ and the pharmacokinetic parameters.

Propranolol, a nonselective $\beta$-adrenoceptor blocking agent, is a lipophilic drug, almost totally absorbed after oral administration. It has an extensive first-pass effect and only about $30 \%$ of active drug reaches the systemic circulation. Inter-individual variation in the presystemic elimination of the drug contributes to the wide range of plasma concentrations detected after oral dosing. Propranolol is a high extraction drug, extensively biotransformed by the liver, and most of its metabolites are excreted in the urine. The biological $\beta$ half-life and plasma clearance of propranolol depend on hepatic blood flow, and thus, they may change when co-administered with other drugs that affect propranolol metabolism and hepatic blood flow (15). Furthermore, the biological $\beta$ half-life of propranolol could have been prolonged as a consequence of hypothermic $\mathrm{CPB}$, since it is well known that CPB can decrease protein plasma drug binding. In the present study, significant increases in unbound drug can explain the apparent volume of distribution increase in the same relative amount as the increase in the elimination half-life.

In contrast, atenolol is a long-acting, selective $\beta 1$ adrenergic cardiac receptor antagonist and after oral administration, despite the lack of presystemic elimination, about 50 to $60 \%$ of the dose is absorbed by the gastrointestinal tract and reaches the blood circulation, with the peak plasma concentration being reached within 2 to 4 $\mathrm{h}$. Due to its high water solubility, atenolol is minimally metabolized by the liver and is almost completely excreted in unaltered form into the urine through glomerular filtration, with a linear correlation demonstrable between atenolol clearance and glomerular filtration rate.

The aromatic ring of the $\beta$-blocker is responsible for the different lipophilicities of the drug molecule and, pharmacokinetically, this influences its protein binding, hepatic extraction ratio and volume of distribution (16). Propranolol binds to plasma proteins more than atenolol, and approximately $90 \%$ of the circulating drug is bound mainly to plasma $\alpha_{1}$-acid glycoprotein (17), with a volume of distribution of $4.30 \mathrm{~L} / \mathrm{kg}$. In contrast, atenolol shows an apparent volume of distribution of $0.95 \mathrm{~L} / \mathrm{kg}$ and less than $5 \%$ binding to plasma proteins.
The utilization of hypothermic CPB during CABG induced alterations in propranolol pharmacokinetics not observed in the pharmacokinetics of atenolol. Acute hemodilution, altered plasma protein binding, hypotension, hypothermia, and rewarming are some of the factors that may change pharmacokinetic properties of propranolol during the intra-operative period and may have important implications in the postoperative period. Immediately after starting $\mathrm{CPB}$, there is a decrease in the plasma concentrations of propranolol, associated with the direct result of hemodilution due to CPB priming volume and to a $40-50 \%$ decrease in plasma protein levels (18). The decrease in plasma proteins may compensate the direct effect of hemodilution on plasma drug concentration by increasing the free drug fraction. For drugs with strong binding to plasma proteins, such as propranolol, hemodilution results in a possible relatively larger increase in the free fraction. This could, therefore, result in a greater transfer of the drug out of the blood/prime mixture to the tissues, and thus a lower total concentration in the blood/prime mixture (19). The decrease in plasma proteins may persist after CPB and an increase in the plasma free fraction of propranolol would be expected in the postoperative period.

Although $\beta$-blockers reduce the incidence of all-cause deaths and sudden cardiac death after myocardial infarction (2), as well as blunting the hemodynamic responses to surgical stimulation when administered preoperatively and also reducing preoperative events among high-risk patients undergoing major noncardiac and vascular surgery $(8,20)$, few studies have examined whether $\beta$-blocker therapy is beneficial when used preoperatively in patients undergoing CABG (21). Extrapolation of the cardioprotective benefits of $\beta$-blockers from major noncardiac and vascular settings to cardiac surgery is reasonable, but there is concern that this treatment, when applied to CABG patients, may be detrimental due to depression of myocardial contractility and/or exacerbation of underlying reactive airway disease. Ferguson et al. (21) analyzed the Society of Thoracic Surgeons National Adult Cardiac Surgery Database from 1996 to 1999 to examine patterns of preoperative use of $\beta$-blockers in patients undergoing isolated $C A B G$ and concluded that preoperative $\beta$-blocker therapy, used in $50-60 \%$ of patients, was associated with a small but consistent survival benefit for patients undergoing CABG, except for patients with a poor left ventricular ejection fraction.

After the studies of Boudoulas et al. $(7,22)$, the maintenance of preoperative $\beta$-blocker therapy became a routine procedure, since it does not modify myocardial performance during the pre- and posthypothermic CPB period. Furthermore, due to the markedly increased adrenergic 
tone on the day before the surgery and the transient hypersensitivity to adrenergic stimulation after withdrawal of propranolol, this agent should be continued until the day before coronary bypass surgery and should be reintroduced in the postoperative period as soon as possible. However, according to the present results, an accumulation of propranolol might be expected in patients undergoing CABG under hypothermic CPB.

The changes in pharmacokinetic parameters of propranolol observed in the present study indicate a prolongation of biological $\beta$ half-life and a 2 -fold increase in volume of distribution after surgery. These alterations in propranolol pharmacokinetics may be responsible for the decrease in the dose required for adequate $\beta$-blockade effects in the postoperative period.

Organ perfusion alterations caused by CPB and hypothermia influence the metabolism and elimination of the drug by the liver and kidneys $(23,24)$. However, in the

\section{References}

1. Gersh BJ, Braunwald E, Rutherford JD. Chronic coronary artery disease. In: Braunwald $\mathrm{E}$ (Editor), Heart disease: $A$ textbook of cardiovascular medicine. Philadelphia: W.B. Saunders Company; 1997. p 1304-1308.

2. Ryan TJ, Antman EM, Brooks NH, Califf RM, Hillis LD, Hiratzka LF, et al. 1999 update: ACC/AHA guidelines for the management of patients with acute myocardial infarction. A report of the American College of Cardiology/American Heart Association Task Force on Practice Guidelines (Committee on Management of Acute Myocardial Infarction). $J$ Am Coll Cardiol 1999; 34: 890-911.

3. Wallace A, Layug B, Tateo I, Li J, Hollenberg M, Browner W, et al. Prophylactic atenolol reduces postoperative myocardial ischemia. McSPI Research Group. Anesthesiology 1998; 88: 7-17.

4. Mangano DT, Layug EL, Wallace A, Tateo I. Effect of atenolol on mortality and cardiovascular morbidity after noncardiac surgery. Multicenter Study of Perioperative Ischemia Research Group. N Engl J Med 1996; 335: 1713-1720.

5. Sill JC, Nugent M, Moyer TP, Torres LE, Schaff HV, Tinker $\mathrm{JH}$. Influence of propranolol plasma levels on hemodynamics during coronary artery bypass surgery. Anesthesiology 1984; 60: 455-463

6. Slogoff S, Keats AS. Does perioperative myocardial ischemia lead to postoperative myocardial infarction? Anesthesiology 1985; 62: 107-114.

7. Boudoulas $H$, Lewis RP, Snyder GL, Karayannacos $P$, Vasko JS. Beneficial effect of continuation of propranolol through coronary bypass surgery. Clin Cardiol 1979; 2: 8791.

8. Mangano DT. Adverse outcomes after surgery in the year 2001 - a continuing odyssey. Anesthesiology 1998; 88: 561564. present study, we cannot assume that the effects of CPB on liver and kidney function played a major role in the changes observed in the pharmacokinetics of propranolol, since the plasma clearance was unchanged. No correlation was observed between the duration of CPB or temperature and the changes in propranolol biological $\beta$ half-life, volume of distribution or total plasma clearance but there was a strong correlation between the increase in biological $\beta$ half-life and volume of distribution. These results also argue in favor of hemodilution and a possible decrease in plasma proteins as the main mechanisms responsible for the changes demonstrated here in the pharmacokinetic parameters of propranolol observed during the postoperative period. More studies comparing propranolol pharmacokinetics in patients undergoing CABG with $\mathrm{CPB}$ to offpump CABG are necessary to further investigate the specific roles of CPB-induced hemodilution and decreased plasma proteins.

9. Miller RR, Olson HG, Amsterdam EA, Mason DT. PropranoIol-withdrawal rebound phenomenon. Exacerbation of coronary events after abrupt cessation of antianginal therapy. $N$ Engl J Med 1975; 293: 416-418.

10. Carmona MJ, Malbouisson LM, Pereira VA, Bertoline MA, Omosako CE, Le Bihan KB, et al. Cardiopulmonary bypass alters the pharmacokinetics of propranolol in patients undergoing cardiac surgery. Braz J Med Biol Res 2005; 38: 713-721.

11. Higgins TL, Estafanous FG, Loop FD, Beck GJ, Blum JM, Paranandi L. Stratification of morbidity and mortality outcome by preoperative risk factors in coronary artery bypass patients. A clinical severity score. JAMA 1992; 267: 23442348 .

12. Pereira VA, Bertoline MA, Carmona MJC, Auler JOC Jr, Santos SRCJ. High performance liquid chromatography to determine propranolol in plasma. Drug accumulation in postsurgical patients. Braz J Pharmac Sci 2000; 36: 241-247.

13. Winer BJ. Statistical principles in experimental design. New York: McGraw-Hill Book Co.; 1971.

14. Singer JM, Andrade DF. Análise de dados longitudinais. Campinas: VII SINAPE; 1986.

15. Hoffman BB, Lefkowitz RJ. Catecholamines, sympathomimetic drugs, and adrenergic receptor antagonist. In: Hardman JG, Limbird LE (Editors), Goodman \& Gilman's - the pharmacological basis of therapeutics. 10th edn. Chicago: McGraw-Hill Companies; 2001. p 215-268.

16. Meier J. Beta-adrenoceptor-blocking agents: pharmacokinetic differences and their clinical implications illustrated on pindolol. Cardiology 1979; 64 (Suppl 1): 1-13.

17. Sager G, Jaeger R, Little C. Binding of prazosin and propranolol at variable alpha 1-acid glycoprotein and albumin concentrations. Br J Clin Pharmacol 1989; 27: 229-234. 
18. Rosen DA, Rosen KR. Elimination of drugs and toxins during cardiopulmonary bypass. J Cardiothorac Vasc Anesth 1997; 11: 337-340.

19. Buylaert WA, Herregods LL, Mortier EP, Bogaert MG. Cardiopulmonary bypass and the pharmacokinetics of drugs. An update. Clin Pharmacokinet 1989; 17: 10-26.

20. Mangano DT. Outcome studies in perioperative medicine: The $\beta$-blockade trials. In: Tuman KJ (Editor), Outcome measurements in cardiovascular medicine. Chicago: Lippincott Williams \& Wilkins; 1999. p 105-124.

21. Ferguson TB Jr, Coombs LP, Peterson ED. Preoperative beta-blocker use and mortality and morbidity following
CABG surgery in North America. JAMA 2002; 287: 22212227.

22. Boudoulas H, Snyder GL, Lewis RP, Kates RE, Karayannacos PE, Vasko JS. Safety and rationale for continuation of propranolol therapy during coronary bypass operation. Ann Thorac Surg 1978; 26: 222-227.

23. McAllister RG Jr, Bourne DW, Tan TG, Erickson JL, Wachtel CC, Todd EP. Effects of hypothermia on propranolol kinetics. Clin Pharmacol Ther 1979; 25: 1-7.

24. McAllister RG Jr, Tan TG. Effect of hypothermia on drug metabolism. In vitro studies with propranolol and verapamil. Pharmacology 1980; 20: 95-100. 